\title{
Tortoise shell and falsify random amplified polymorphism DNA (RAPD) appraisal method research
}

\author{
Li Zi-tong, a, Yuan Guang-xin ${ }^{1, b}$, Wang Miao, c, Gao Li-jun ${ }^{2, d}$, Zhang Li-hua ${ }^{3,}$ \\ ${ }^{e}$, Li Ming-cheng ${ }^{2, f}$ and Niu Jia-mu ${ }^{4,}{ }^{*}$ \\ ${ }^{1}$ College of Pharmacy, Beihua University, Jilin, Jilin 132013, PR China \\ ${ }^{2}$ School of Laboratory Medicine, Beihua University, Jilin, PR China \\ ${ }^{3}$ LeiBo Technology Co., Ltd., Jilin, PR China \\ ${ }^{4}$ Department of Research, Beihua University, Jilin, Jilin 132013, PR China; \\ a516314302@qq.com, byuanguangxin2007@163.com, cbhdxwm@163.com, \\ d348050763@qq.com, 1592123431@qq.com, '576466156@qq.com, 9957918240@qq.com
}

Keywords: Tortoise shell; PCR; RAPD; Fingerprint.

Abstract. Purpose To establish a practical, fast and accurate identification method of tortoise shell, falsify amplified polymorphism DNA (RAPD) randomly and provide reliable basis for identification of tortoise shell. Method We use the Alkali cracking method to extract mitochondrial DNA from the tortoise shell and falsify and randomly do the amplification polymorphic DNA. Result The electrocardiogram of genuine and counterfeit goods tortoise shells mitochondrial DNA random amplified has obvious difference, the stripe number and location are all different, this method can effectively distinguish between genuine and counterfeit goods tortoise shells. Conclusion RAPD technology provides a simple, effective, high reliability for the identification of tortoise shell and its adulterants.

\section{Introduction}

Tortoise shell is the turtle carapace and shell of testudinidae animal [Chinemys reevesii (Gray) ]. It has the effects of nourishing and suppressing Yang, kidney strong bone, nourishing blood bushing, fixed by the effect of collapse. Commonly it is used in Yin deficiency hot flashes, bone steaming, night sweats, dizzy, within the virtual wind, bones and muscles impotent soft, guilty forgetful, ren classics ${ }^{[1]}$. At present, it appears complex kinds of tortoises on the market, falsifies mainly include Indotestudo elongata, Manouria impressa, Mauremys mutica, Cuora amboinensis, Cuora galbinifrons etc, with the close sources of the tortoise, it brings certain difficulties to the traditional physical and chemical identification methods, and with the increase in demand, it appears more and more shoddy phenomenon to cause great harm to the patients.

DNA fingerprinting is a method of using DNA to identify species at the molecular level, it has highly germplasm specificity and more scientific and accurate than traditional Chinese medicine appraisal method $^{[2,3]}$. The technique of random amplified polymorphism DNA (RAPD), has rich polymorphism, less dosage of DNA amplification results and no special design primers. In recent years, it has been widely used in species identification ${ }^{[4,5]}$. This experiment uses RAPD technology research tortoise shell and falsify DNA fingerprint, provides a tortoise shell and falsify the identification of new method is rapid, simple and accurate.

\section{Apparatus and materials}

DYY-7C Horizontal Electrophoresis Apparatus (Beijing Six One Instrument Plant), DYY-8B Stabilized Horizontal Electrophoresis Apparatus (Beijing Six One Instrument Plant) , H-2050R Desktop High-speed Centrifuge at Low Temperature (American Becman company), SHA-B Thermostatic oscillator (The jintan city, jiangsu province medical instrument factory), UV WHITE2020D Gel imaging analysis system (The Bio-Rad company in America), UV759 Uv-vis 
spectrophotometer (Beijing's general instrument co., LTD), WD-9406 Film observation lamp (Beijing Six One Instrument Plant), ZF UV transmission (Shanghai Jia Peng Technology Co., Ltd.) , 9700 PCR amplification (American ABI company) .

10-mer primers were synthesized by Shanghai Generay biotech Co. Ltd., Marker 100bp DNA Ladder, MarkerVII, $\lambda$-Hind III DNA Marker purchased from the day root biochemical technology (Beijing) Co. Ltd., Agarose purchased from the Spanish Agrose company, 6×Loading Buffer, $10 \times$ PCR buffer, Rnase, EB purchased from Beijing tripod state Biological Technology Co. Ltd., DNA Taq polymerase purchased from Dalian Bao bio engineering company, dNTPs purchased from the Fermentas companies in the United States, other reagents were analytical pure, the water for the home-made sterile double distilled water.

We collected five batches of commercially available varieties of shells and four batches of samples.

\section{Experimental method}

\section{the extraction of shells mitochondrial DNA}

Get the right amount of tortoise shell sample, clean, dry, grind into powder in mortar. Take $10 \mathrm{~g}$ and add Buffer $\mathrm{A}$ in the $20 \mathrm{ml}$ beaker to full grind after slight shaking in the mortar, drain all the slurry in the EP tube, under $4{ }^{\circ} \mathrm{C}, 3000 \mathrm{r} \cdot \mathrm{min}^{-1}$ centrifugal $15 \mathrm{~min}$, take the supernatant. Abandon the supernatant again, collect precipitation in the EP tube. Add $0.5 \mathrm{ml}$ Buffer B after the suspension, under $4{ }^{\circ} \mathrm{C}$, $15000 \mathrm{r} \cdot \mathrm{min}^{-1}$ centrifugal $15 \mathrm{~min}$, repetitive operation. Add $0.5 \mathrm{ml}$ DNA enzyme $(10 \mathrm{mg} / \mathrm{ml})$ in $37{ }^{\circ} \mathrm{C}$ oven in $45 \mathrm{~min}$. In ice bath, add 2 times the volume of DNA I terminated liquid, under $4{ }^{\circ} \mathrm{C}$, $15000 \mathrm{r} \cdot \mathrm{min}^{-1}$ centrifugal $20 \mathrm{~min}$, abandon the supernatant, precipitation with DNA I terminated liquid washing after 1 time, under $4{ }^{\circ} \mathrm{C}, 15000 \mathrm{r} \cdot \mathrm{min}^{-1}$ centrifugal $20 \mathrm{~min}$, abandon the supernatant, join in precipitation $0.5 \mathrm{ml}$ Buffer and $40 \mathrm{C}$ ul SDS, put in the oven, $37{ }^{\circ} \mathrm{C}$ for $10 \mathrm{~min}$. (In the fume hood operation) Ice bath, to join in EP tube $0.54 \mathrm{ml}$ saturation of phenol, mild concussion, make its white, after $30 \mathrm{~min}$, under $4{ }^{\circ} \mathrm{C}, 15000 \mathrm{r} \cdot \mathrm{min}^{-1}$ centrifugal $10 \mathrm{~min}$, take the water phase, repeat until extract interface without protein. To the water phase in chloroform: isoamyl alcohol mixture (480 ul:20 ul), under $4{ }^{\circ} \mathrm{C}, 15000 \mathrm{r} \cdot \mathrm{min}^{-1}$ centrifugal $10 \mathrm{~min}$, repeat 2 times. Take the $0.1 \mathrm{ml} \mathrm{NaAc}$ to the water phase, shake well. And then add equal volume of anhydrous ethanol, $-20{ }^{\circ} \mathrm{C}$ for the night. After about 18 hours, after $4{ }^{\circ} \mathrm{C}, 15000 \mathrm{r} \cdot \mathrm{min}^{-1}$ centrifugal $20 \mathrm{~min}$ abandon solution, will buckle the EP tube on filter paper, drying at room temperature. (about 3 hours) Add $50 \mathrm{ul} \mathrm{TE}, 50 \mathrm{ul}$ RNA enzymes, placed $1 \mathrm{~h}$ at $37{ }^{\circ} \mathrm{C}$ oven, save to $-20{ }^{\circ} \mathrm{C}$.

\section{the mtDNA purity and concentration measurement}

Ultraviolet spectrophotometer is used to test $260 \mathrm{~nm}$ and $280 \mathrm{~nm}$ absorbance wavelengths of the dilute mtDNA appropriately, in terms of $\mathrm{A}_{260} / \mathrm{A} 280$ tortoiseshell mtDNA purity and concentration.

\section{Analysis of shells of mtDNA agarose gel electrophoresis}

The mtDNA extracted blending with 6 x Loading buffer (6:1), sample points on $0.8 \%$ agarose gel plate, electrophoresis voltage $50 \mathrm{~V}, 60 \mathrm{~min}$, electrophoresis time by ultraviolet detection.

\section{RAPD amplification and detection}

Random primers

Purchased from Shanghai jie rui biological engineering co. LTD. 10-mer random primers screened primer sequences are shown in Table 1. 
Table 1 Sequences of primers

\begin{tabular}{cl}
\hline Name of random primers & Random primers \\
\hline S1 & GTTTCGCTCC \\
S2 & TGCGCCCTTC \\
S3 & CCTTGACGCA \\
S4 & CATTCGAGCC \\
S5 & AATGCCCCAG \\
S6 & CCCGCTACAC \\
S7 & GGTTGTACCC \\
S8 & CTCCTGCCAA \\
S9 & CCCAGCTGTG \\
S10 & GTGTCGCGAG \\
\hline
\end{tabular}

RAPD amplification system

The mtDNA of tortoise shell samples was used as template, sterile double distilled water as a negative control, polymerase chain PCR reaction ${ }^{[7]}$, reaction system as shown in Table 2.

Table 2 Reaction system

\begin{tabular}{cc}
\hline The reagent & The volume \\
\hline 2×Taq PCR Master Mix & $12.5 \mu \mathrm{l}$ \\
Primer(12.5 $\mu \mathrm{mol} / \mathrm{L})$ & $1.0 \mu \mathrm{l}$ \\
DNA template & $2.0 \mu \mathrm{l}$ \\
ddH2O & $9.5 \mu \mathrm{l}$
\end{tabular}

Each tube $25 \mu 1$ reaction system, blend to shake, hand-held centrifuge briefly centrifugal to no bubble.

RAPD amplification conditions

PCR circulation parametersr: pre modified $5 \min \left(94{ }^{\circ} \mathrm{C}\right)$, modified $80 \mathrm{~s}\left(94{ }^{\circ} \mathrm{C}\right)$, annealing $1 \mathrm{~min}$ $\left(36^{\circ} \mathrm{C}\right)$, extended $2 \min \left(72{ }^{\circ} \mathrm{C}\right), 40$ cycle extended again after $10 \min \left(72{ }^{\circ} \mathrm{C}\right)$. PCR products save under $4{ }^{\circ} \mathrm{C}$.

RAPD amplification products agarose gel electrophoresis analysis

Put the PCR amplification product sample on $2 \%$ agarose gel plate, voltage $80 \mathrm{~V}$, electrophoresis $110 \mathrm{~min}$, by ultraviolet detection.

\section{The results and analysis}

\section{DNA purity and concentration}

By uv-vis spectrophotometer detection, $\mathrm{A}_{260} / \mathrm{A}_{280}$ between $1.694 \sim 1.805$, the results show that tortoise shell mitochondrial DNA is of high purity, elementary no protein pollution and can be used for PCR amplification (Table 3.) .

Table 3 The purity and concentration of DNA

\begin{tabular}{ccccc}
\hline The sample name & $\mathrm{A}_{260}$ & $\mathrm{~A}_{280}$ & The purity & The Concentratio $\left(\mathrm{ug} \cdot \mathrm{L}^{-1}\right)$ \\
\hline No. 1 genuine shells & 0.527 & 0.305 & 1.728 & 0.264 \\
No. 2 genuine shells & 0.358 & 0.199 & 1.799 & 0.358 \\
Indotestudo elongata & 0.506 & 0.287 & 1.763 & 0.253 \\
Graptemys & 0.533 & 0.308 & 1.731 & 0.267 \\
Trachemys scripta elegans & 0.537 & 0.317 & 1.694 & 0.269 \\
Commercially available shells $\mathrm{S}_{1}$ & 0.374 & 0.212 & 1.765 & 0.374 \\
Commercially available shells $\mathrm{S}_{2}$ & 0.361 & 0.208 & 1.737 & 0.361 \\
Commercially available shells $\mathrm{S}_{3}$ & 0.390 & 0.217 & 1.805 & 0.390 \\
Commercially available shells $\mathrm{S}_{4}$ & 0.119 & 0.067 & 1.776 & 0.119 \\
\hline
\end{tabular}




\section{Agarose gel electrophoresis analysis of sample mtDNA shells}

From Fig. 1 shows that extracted from the shells of all the samples of mitochondrial DNA bands were clear and complete, no obvious diffusion and degradation, relative molecular weight is about 16. $6 \times 10^{3}$, it shows that the bond cleavage method can get complete, high purity of the mitochondrial DNA from the tortoise shell, the RAPD amplification stability provides a structure based.

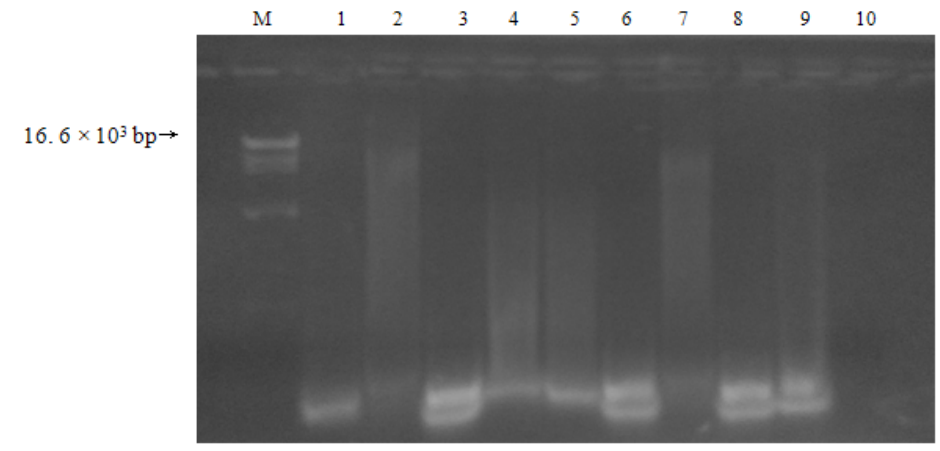

Fig.1 Agarose gel electrophoresis of mtDNA extract from turtle shells

M:marker;1:No.1 genuine shells;2:No.2genuine shells;3:Indotestudo elongata;4:Graptemys; 5:Trachemys scripta elegans;6:Commercially available shells S1;7:Commercially available shells S2;

8:Commercially available shells S3;9:Commercially available shells S4;10:Blank;M:marker

\section{Primers screening results}

After many experimental screening, select primers S6 (CCCGCTACAC) PCR amplification reaction, the result of the primer amplification polymorphism is rich, strong specificity and good repeatability, clear amplification bands, band number is moderate, can be used for the preparation of tortoise shell DNA fingerprint.

\section{Amplification of tortoiseshell mitochondrial DNA-RAPD agarose gel electrophoresis}

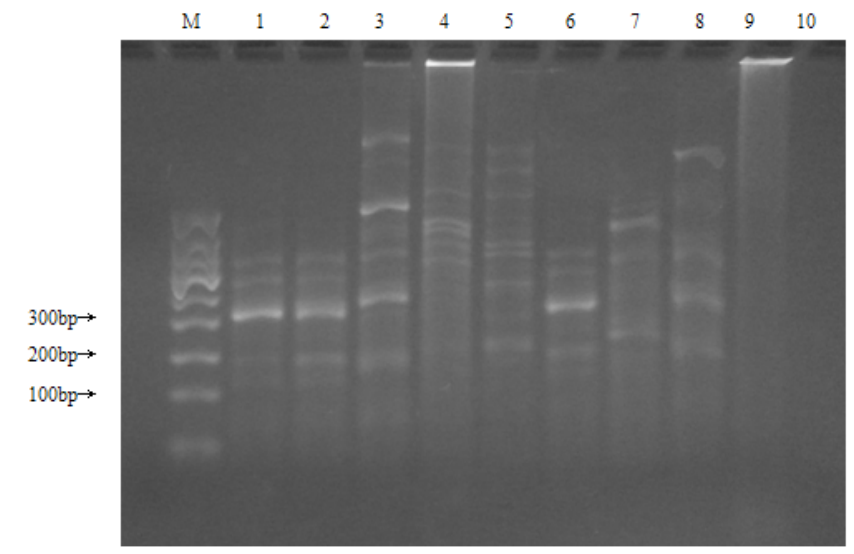

Fig.2 Agarose gel electrophoresis of PCR producs

M:marker;1:No.1 genuine shells;2:No.2genuine shells;3:Indotestudo elongata;4:Graptemys; 5:Trachemys scripta elegans;6:Commercially available shells S1;7:Commercially available shells S2;

8:Commercially available shells S3;9:Commercially available shells S4;10:Blank

From Fig. 2 and RAPD amplification of electrophoretogram of RAPD from the RAPD amplification which S6 (CCCGCTACAC) as the primers, the electrophoresis results of two genuine shells are basically the same, with the quantity and position of the same, in about 100bp, 200bp and 300bp at has three characteristic bands, only with brightness slightly to have the difference. While Myanmar tortoises, map turtles, Brazil red eared turtle genuine shells electrophoresis has the obvious difference, the band number and location are different. The 4 batch of commercially available samples, $S_{2}, S_{3}$ and $\mathrm{S}_{4}$ electrophoresis and genuine shell electrophoresis have the obvious difference, can be identified as counterfeit tortoise. This method can effectively distinguish between genuine and counterfeit goods tortoiseshells. 


\section{Discussion}

DNA fingerprinting is a genetic marker for identification of objects at the molecular level. It has the advantages of high specificity and low sample size. It is very suitable for the identification of varieties of Chinese medicine (especially valuable Chinese herbal medicine) ${ }^{[8,9]}$. Random amplified DNA polymorphism analysis (RAPD) technology can be used in the identification of varieties resources because it can study the construction of DNA fingerprinting and genetic diversity of a species. At present, the relevant research reports on the construction of DNA fingerprinting by RAPD technology at home and abroad.

RAPD fingerprint is established in this experiment by studying the differential shell, of tortoiseshell at DNA molecular level. 1 primer is screened from 10 primers. The amplified results polymorphism abundant and amplified with strong specificity and good repeatability can accurately distinguish the tortoise shell and its adulterants. The method is simple, reliable and reproducible, and it is consistent with the requirements of fingerprint. Identification of tortoiseshell varieties have certain significance and practical value, provides a more ideal method for the evaluation and control the quality of the tortoise plastron.

But due to the collection of tortoiseshell relatively few volume of sample, RAPD fingerprinting of the established stability and applicability should be also further verified. By further research, it is hoped to establish a fast identification method which can be widely used in the easily confused Chinese herbal medicine.

\section{Acknowledgement}

This work was supported by the Jilin province high technology industry development (2013G030) and Jilin health family planning research plan (2014Z085) and Jilin provincial economic structure strategic adjustment lead special projects (2015Y077) .

\section{References}

[1] Ch. P (2010) Vol I (Chinese Pharmacopoeia 2010 edition.) [S] . 2010:168.

[2] Tong-hui, WANG Jin, LI Ming-cheng, etc. Identification of Cytochrome b Bene of Chinese Herb Testudinis Carapax et Plastrum [J] . Chinese Pharmaceutical Journal, 2012, 47(3) : $182 \sim 185$.

[3] TAN Ying, ZHANG Li-hua, LI Ming-cheng, etc. Identification of Chinese Herb Fritillaria cirrhosa

D. Don by DNA Fingerprint [J] . Chinese Pharmaceutical Journal, 2011, 46 (1) : 14 16.

[4] Cao Ya-nan, Li Qing-zhang, Sun yue, etc. RAPD and ISSR analysis of genetic diversity of genuine gentian [J] . Chinese herbal medicine, 2005, 36(1) : 100-103

[5] Tan ying, Zhang Li-hua, Li Ming-cheng, etcChinese herbal medicine unibract fritillary bulb DNA fingerprint [J] . Chinese Pharmaceutical Journal 2011, 46(1) : 14-16.

[6] Sun Jing-yu, Zhang Lu-hua, Fu Gui-lian, etc. Polymerase chain reaction coupling single-strand conformation polymorphism analysis (PCR-SSCP) technology for deer whip mitochondrial DNA fingerprints of research [J]. Chinese Pharmaceutical Journal, 2014, (9) : 721 725.

[7] J.Sambrook, E.F.Fritsch T. Mamiatis. Molecular Cloning, [M]. Cold Spring Harbor Laboratory Press, 1989: 49 59.

[8] Sun Jing-yu, Zhang Li-hua, Fu Gui-lian, etc. Polymerase chain reaction coupling analysis of single-strand conformation polymorphism (PCR - SSCP) technology used in the study of tortoise shell mitochondrial DNA fingerprints [J]. Chinese Pharmaceutical Journal, 2014, (9) : 721 725. 
International Forum on Energy, Environment Science and Materials (IFEESM 2015)

[9] GU Y G, ZHANG L H, FU G L. Identification of velvet antler by mitochondrial DNA fingerprint [J]Chin Pharm J, 2013, 48(3) : 170-173. 